\title{
ERS Scientific Working Group 09.04, "Psychologists and behavioural scientists": the next step towards multidisciplinary respiratory care
}

\author{
Andreas von Leupoldt (10), Lisa Jane Brighton (10) ${ }^{2}$, Jeannette Peters ${ }^{3}$, \\ Eleonora Volpato ${ }^{4,5}$, Marieke Verkleij ${ }^{6}$, Ann Hutchinson ${ }^{7}$, Monique Heijmans ${ }^{8}$, \\ Ingeborg Farver-Vestergaard ${ }^{9}$, Daniel Langer (10 ${ }^{10}$ and Martijn A. Spruit (1) ${ }^{11,12,13}$, \\ on behalf of the ERS Scientific Working Group 09.04
}

\begin{abstract}
Affiliations: ${ }^{1}$ Health Psychology, University of Leuven, Leuven, Belgium. ${ }^{2}$ Cicely Saunders Institute of Palliative Care, Policy and Rehabilitation, King's College London, London, UK. ${ }^{3}$ Dept of Medical Psychology and Dept of Lung diseases, Radboud University Medical Center, Radboud Institute for Health Sciences, Nijmegen, The Netherlands. ${ }^{4}$ Dept of Psychology, Università Cattolica del Sacro Cuore, Milan, Italy. ${ }^{5}$ IRCCS Fondazione Don Carlo Gnocchi, Milan, Italy. ${ }^{6}$ Dept of Paediatric Psychology, Amsterdam UMC, Vrije Universiteit Amsterdam, Amsterdam, The Netherlands. ${ }^{7}$ Hull York Medical School, University of Hull, Hull, UK. ${ }^{8}$ Netherlands Institute for Health Services Research (Nivel), Utrecht, The Netherlands. ${ }^{9}$ Dept of Medicine, Vejle Hospital, Hospital Little Belt, Vejle, Denmark. ${ }^{10}$ Faculty of Kinesiology and Rehabilitation Sciences, Dept of Rehabilitation Sciences, Research Group for Cardiovascular and Respiratory Rehabilitation, KU Leuven University of Leuven, and Respiratory Rehabilitation and Respiratory Division, University Hospital Leuven, Leuven, Belgium. ${ }^{11}$ Dept of Research and Development, CIRO, Horn, The Netherlands. ${ }^{12}$ Dept of Respiratory Medicine, Maastricht University Medical Centre (MUMC+). NUTRIM School of Nutrition and Translational Research in Metabolism, Maastricht, The Netherlands. ${ }^{13}$ Reval Rehabilitation Research, Biomedical Research Institute, Faculty of Rehabilitation Sciences, Diepenbeek, Belgium.
\end{abstract}

Correspondence: Andreas von Leupoldt, Health Psychology, University of Leuven, Tiensestraat 102, B-3000 Leuven, Belgium. E-mail: andreas.vonleupoldt@akuleuven.be

@ERSpublications

The new ERS Scientific Working Group 09.04 "Psychologists and Behavioural Scientists" will support psychological and behavioural aspects of respiratory care, in order to improve multidisciplinary clinical practice, education, and research https://bit.ly/2OPJF0U

Cite this article as: von Leupoldt A, Brighton LJ, Peters J, et al. ERS Scientific Working Group 09.04, "Psychologists and behavioural scientists": the next step towards multidisciplinary respiratory care. Eur Respir J 2020; 56: 2001881 [https://doi.org/10.1183/13993003.01881-2020].

Impaired lung function is a cardinal feature in people with various chronic respiratory diseases, which is predominantly treated pharmacologically with additional smoking cessation if appropriate. Despite optimal medical treatment, many people with respiratory disease still experience daily physical, psychological and social limitations [1,2]. As the degree of lung function impairment only partially explains these daily limitations, diagnostics and management must focus beyond biomedical and pharmacological approaches. Therefore, the role of allied respiratory professionals is essential within comprehensive disease management programmes, including adequate diagnostics, disease monitoring, and tailored non-pharmacological therapy options.

Scientific and educational activities around allied respiratory care are covered by European Respiratory Society (ERS) Assembly 9 "Allied Respiratory Professionals", which has consisted so far of three scientific 
working groups: 09.01 "Respiratory Function Technologists/Scientists", 09.02 "Physiotherapists", and 09.03 "Nurses". During the ERS General Assembly meeting, which took place during the virtual ERS International Congress 2020, a new ERS Assembly 9-related scientific working group was ratified: 09.04 "Psychologists and Behavioural Scientists". So, the ERS and its Assembly 9 are taking the next step towards multidisciplinary respiratory care, by fostering scientific and educational activities around psychology and behaviour change across the eight main disease domains: airway diseases, interstitial lung diseases, paediatric respiratory diseases, pulmonary vascular diseases, respiratory critical care, respiratory infections, sleep and breathing disorders, and thoracic oncology. This scientific working group is inclusive of individuals with a variety of professional backgrounds who support psychological and behavioural aspects of respiratory care, in order to improve clinical practice, education and research. In this editorial, we introduce the added value of the future ERS scientific working group 09.04.

\section{The clinical relevance of psychology and behaviour change}

People with chronic respiratory diseases not only experience prominent respiratory symptoms, but additionally those related to multiple comorbidities [3-8]. They more often live in deprived communities with poor housing and poor air quality, and experience reduced social support and loneliness [9, 10]. These multidimensional factors can strongly contribute to and perpetuate cognitive impairments and psychological symptoms, create barriers to adaptive health behaviours and significantly contribute to the burden of the disease, affecting quality of life often in a downward spiral [11, 12]. The net effects are substantial reductions in the quality of life for those with chronic respiratory disease, their families and informal caregivers $[12,13]$, together with high socioeconomic costs [14].

Nevertheless, people with chronic respiratory disease must continually adapt and learn to live with their respiratory and non-respiratory symptoms, and concomitant comorbidities, in their given social environments $[15,16]$. Preferably, this happens with optimal medical and therapeutic support from formal and informal caregivers. This chronic care management is an essential but highly complex practice, especially in the era of personalised treatments $[1,4,11]$. Alongside the "classical" medical and therapeutic components, support preferably involves further important elements, such as guided self-management, psychosocial interventions and behaviour change techniques, supported by a multidisciplinary team $[2,9$, 12, 17-19]. However, psychosocial and behavioural factors are still considerably under-recognised in chronic respiratory care and research, thus limiting the availability of comprehensive, integrated and holistic treatments and preventing optimal treatment effects $[4,11,20]$. Therefore, the new ERS scientific working group 09.04 is of great added value from a clinical, scientific and educational perspective.

\section{Management of psychological symptoms}

Various studies have demonstrated that comorbid psychological symptoms are very common in individuals with chronic respiratory conditions $[9,21,22]$. For example, in people with asthma, symptom prevalence rates have been estimated at between $7 \%$ and $26 \%$ for anxiety and between $22 \%$ and $45 \%$ for depression, with higher rates typically being observed in more severe asthma forms [23, 24]. In people with COPD, questionnaire-based pooled prevalence rates for symptoms of anxiety and depression of $36 \%$ and $40 \%$, respectively [25], have been reported in meta-analyses, although these rates can range across studies between $2 \%$ and $80 \%$, depending on the diagnostic tool used and the specific subgroups of people [22]. When using the gold standard of DSM criteria-based clinical interviews, these pooled prevalence rates are somewhat lower (26\% and $19 \%)$, but still about three times higher than in non-COPD control groups [26]. In addition, the burden of chronic disease can result in more specific, disease-related distress, for example fear and subsequent avoidance of dyspnoea and/or physical activities [27-29]. In both cases, psychological distress can have a major negative impact on the course of disease and the disease management. These detrimental associations include more frequent exacerbations and (re)hospitalisations, increased inflammation and smoking behaviour, increased symptom burden and use of short-acting reliever medication, decreases in physical and social functioning, reduced quality of life and activity levels, less favourable outcome of pulmonary rehabilitation and increased mortality $[9,21,28,30,31]$.

Notably, in everyday clinical practice, comorbid psychological symptoms and distress remain undetected and untreated in more than $50 \%$ and $70 \%$ of people with asthma and COPD, respectively [32, 33]. This also holds for informal caregivers of people with chronic respiratory disease, who often show a high level of psychological burden in the absence of adequate support [12, 13, 34]. In this regard, psychologists and behavioural scientists have a key role in the prevention, detection and treatment of psychological symptoms and distress. They are crucial to the development, implementation and evaluation of psychological interventions. These range from traditional cognitive behavioural approaches to newer acceptance-based models, which have been shown to be effective in several studies, but still need intensified further research [23, 29, 35-39]. This includes not only delivering specialist approaches when required, but also providing supervision to support other multidisciplinary healthcare professionals and 
informal caregivers who provide generalist psychological support. When successfully applied, these interventions can not only reduce psychological symptoms and distress in people with chronic respiratory disease and informal caregivers, but also create positive downstream effects on self-management, functional disease outcomes, quality of life and healthcare costs [37-40].

\section{Management of cognitive dysfunction}

It is well known that cognitive and neuropsychological functions are adversely related to several factors such as hypoxia, hypercapnia, inflammatory processes and sleep fragmentation that characterise several chronic respiratory diseases [41]. Not surprisingly, people affected by chronic respiratory diseases show an increased risk of developing deficits in several cognitive functions (e.g. attention, mental flexibility, reasoning, memory and information processing speed) and developing mild cognitive impairment [41-43]. For example, a recent Dutch study demonstrated that of 183 people with COPD referred for pulmonary rehabilitation, $42 \%$ suffered from cognitive impairment as measured in a detailed neuropsychological test battery, and this prevalence was unrelated to the severity of COPD [44]. These cognitive dysfunctions represent a substantial burden on the affected person, their family and society and are associated with worse health status, greater risk of (longer) hospitalisation for respiratory problems, and increased mortality [21]. In clinical as well as home settings, cognitive impairment can influence both uptake of treatments as well as self-management, for example taking the adequate dose of the correct medication for the right (comorbid) symptoms at the correct moment. However, routine screenings for and potential treatments of cognitive impairments in people with chronic respiratory diseases are widely absent in clinical reality. Psychologists and behavioural scientists with training in cognitive functioning and neuropsychology represent an important profession in the development, scientific exploration and implementation of specific cognitive screening procedures and the management of cognitive dysfunction in respiratory care, alongside their multidisciplinary colleagues [18].

\section{Opportunities for the European Respiratory Society}

In addition to supporting diagnosis and treatment of psychological symptoms and cognitive dysfunction in people with chronic respiratory diseases, the formation of the new ERS scientific working group 09.04 provides a number of additional opportunities for the society, which might further be helpful in attracting new members.

First, the personalised treatment of chronic respiratory symptoms, and of the frequent comorbid physical, cognitive and psychological symptoms, often requires a complex and tailored management that exceeds traditional pharmacological approaches $[1,4,11,12]$. This is increasingly important as the population ages, and people live with multiple chronic conditions alongside their respiratory disease [45]. In most cases, services must support several important behavioural changes in many areas of life for people with chronic respiratory disease, their informal caregivers and even their wider communities, which can be particularly challenging when health literacy is low. Examples include smoking cessation, avoidance of triggers and air pollution, increases in physical and social activities, early and adequate exacerbation management and dietary changes. To achieve these changes, usually new, individually tailored behavioural skills have to be learnt, such as regular self-monitoring of symptoms, adequate drug delivery and inhaler techniques, bronchial hygiene and breathing techniques, activity planning and pacing, sleep management techniques, and/or relaxation or stress management techniques $[9,29,31]$. Often, behavioural changes are supported within self-management training or during larger multidisciplinary programmes, such as pulmonary rehabilitation. These interventions have a convincing evidence base for beneficial effects on symptoms, hospitalisation rates, quality of life and exercise capacity [17, 46]. Many psychologists and behavioural scientists are formally trained in the assessment of needs and the application of individually tailored behaviour change techniques and self-management interventions that may contribute to effective multidisciplinary programmes. Their intensified and more coordinated involvement in the development, implementation and evaluation of such interventions is therefore a major opportunity. In close cooperation with other multidisciplinary colleagues, this can include a role for psychologists and behavioural scientists in supporting the education and training of other health professionals in the appropriate application and high-quality evaluation of interventions to promote cognitive and psychosocial wellbeing, and to support and enable people to participate in behaviour change and self-management.

Second, the visibility and utilisation of psychologists and behavioural scientists among respiratory care professionals, as illustrated above, is still limited. This was also evidenced by an international survey among members of the ERS, American Thoracic Society (ATS) and American Association of Cardiovascular and Pulmonary Rehabilitation on the content of pulmonary rehabilitation programmes [47]. A dedicated group within the ERS can, therefore, not only increase the visibility and involvement of these professions, but also foster collaborations with other ERS assemblies and groups, for example 01.02 "Rehabilitation and Chronic Care", 04.02 "Sleep and Control of Breathing" and 06.03 "Tobacco, Smoking 
Control and Health Education". These collaborations might additionally support the dissemination of dedicated research methodology, such as advanced statistical analyses and neuropsychological measures across the ERS network.

Third, the new group 09.04 may also be an opportunity when it comes to mental health issues in respiratory health care professionals. Psychological symptoms, distress and burnout are not only prevalent and important to be recognised in people with respiratory disease, but also in all types of professionals involved in their care $[48,49]$. This is currently an underserved area both within and outside ERS and members of this group are well positioned to develop respective programmes.

Finally, the group can also be a point of contact and exchange between ERS and other international networks, such as the ATS Assembly on Behavioural Research, the International Society on the Advancement of Respiratory Psychophysiology, the American Psychosomatic Society, the International Society for Behavioral Medicine or other national organisations, respectively. Such networks can ensure that psychological and behavioural research and practice with people affected by respiratory disease builds on, and integrates with, the best of existing work in respiratory and psychological sciences.

Taken together, we are convinced that the formation of the new ERS scientific working group 09.04 will contribute to an urgently needed, increased awareness of psychosocial factors and behaviour change in the care of people with chronic respiratory diseases. This will be a next important step towards more effectively addressing the multidimensional needs of people with chronic respiratory disease and their caregivers in the future, with the ultimate goal of optimising the effects of truly personalised multidisciplinary treatments.

Acknowledgements: Thank you to the following individuals who also contributed to previous written statements supporting the role of psychologists and behavioural scientists in the ERS: Latinka Basara, Julie Boiche, Paul Cafarella, Tanja Effing, Lidia Gazzi, Maureen George, Samantha Harrison, Carmen Houben, Thomas Janssens and Christianna Kyriacou.

Conflict of interest: A. von Leupoldt reports grants from Research Foundation - Flanders (FWO) Belgium, Research Foundation - Flanders (FWO) and Research Fund KU Leuven, Belgium, and Flemish Government, Belgium, during the conduct of the study. L.J. Brighton has nothing to disclose. J. Peters has nothing to disclose. E. Volpato has nothing to disclose. M. Verkleij has nothing to disclose. A. Hutchinson has nothing to disclose. M. Heijmans has nothing to disclose. I. Farver-Vestergaard reports personal fees from AstraZeneca, Boehringer Ingelheim, Novartis and Roche, outside the submitted work. D. Langer has nothing to disclose. M.A. Spruit reports grants from Netherlands Lung Foundation and Stichting Astma Bestrijding, grants and personal fees from AstraZeneca and Boehringer Ingelheim, outside the submitted work.

Support statement: A. von Leupoldt is supported by research grants from the Research Foundation - Flanders (FWO), Belgium (GOA4516N and GOA3718N), by an infrastructure grant from the FWO and the Research Fund KU Leuven, Belgium (AKUL/19/06; I011320N), and by the "Asthenes" long-term structural funding Methusalem grant (METH/15/ 011) by the Flemish Government, Belgium. L.J. Brighton is supported through a National Institute for Health Research (NIHR) Career Development Fellowship (CDF-2017-10-009) held by Matthew Maddocks. Funding information for this article has been deposited with the Crossref Funder Registry.

\section{References}

1 Agusti A, Bel E, Thomas M, et al. Treatable traits: toward precision medicine of chronic airway diseases. Eur Respir J 2016; 47: 410-419.

2 McDonald VM, Fingleton J, Agusti A, et al. Treatable traits: a new paradigm for 21st century management of chronic airway diseases: Treatable Traits Down Under International Workshop report. Eur Respir J 2019; 53: 1802058 .

3 Global Initiative for Chronic Obstructive Lung Disease (GOLD). (2019) Global Strategy for Diagnosis, Management, and Prevention of COPD. https://goldcopd.org Date last accessed: 1 April 2020.

4 Houben-Wilke S, Augustin IM, Vercoulen JH, et al. COPD stands for complex obstructive pulmonary disease. Eur Respir Rev 2018; 27: 180027.

5 Global Initiative for Asthma (GINA). (2019) Global Strategy for Asthma Management and Prevention. https:// ginasthma.org. Date last accessed: 1 April 2020

6 Birring SS, Kavanagh JE, Irwin RS, et al. Treatment of interstitial lung disease associated cough: CHEST guideline and expert panel report. Chest 2018; 154: 904-917.

7 Galiè N, Humbert M, Vachiery J-L, et al. 2015 ESC/ERS Guidelines for the diagnosis and treatment of pulmonary hypertension: The Joint Task Force for the Diagnosis and Treatment of Pulmonary Hypertension of the European Society of Cardiology (ESC) and the European Respiratory Society (ERS). Eur Heart J 2016; 37: 67-119.

8 Leduc C, Antoni D, Charloux A, et al. Comorbidities in the management of patients with lung cancer. Eur Respir J 2017; 49: 1601721 .

9 Ritz T, Meuret AE, Trueba AF, et al. Psychosocial factors and behavioral medicine interventions in asthma. J Consult Clin Psychol 2013; 81: 231-250.

10 Reijnders T, Schuler M, Jelusic D, et al. The impact of loneliness on outcomes of pulmonary rehabilitation in patients with COPD. COPD 2018; 15: 446-453.

11 Spathis A, Booth S, Moffat C, et al. The Breathing, Thinking, Functioning clinical model: a proposal to facilitate evidence-based breathlessness management in chronic respiratory disease. NPJ Prim Care Respir Med 2017; 27: 27. 
12 Hutchinson A, Barclay-Klingle N, Galvin K, et al. Living with breathlessness: a systematic literature review and qualitative synthesis. Eur Respir J 2018; 51: 1701477.

13 Nakken N, Janssen DJA, van den Bogaart EHA, et al. Informal caregivers of patients with COPD: Home Sweet Home? Eur Respir Rev 2015; 24: 498-504.

14 Wacker ME, Kitzing K, Jörres RA, et al. The contribution of symptoms and comorbidities to the economic impact of COPD: an analysis of the German COSYCONET cohort. Int J Chron Obstruct Pulmon Dis 2017; 12: 3437-3448.

15 Goërtz YMJ, Spruit MA, Van 't Hul AJ, et al. Fatigue is highly prevalent in patients with COPD and correlates poorly with the degree of airflow limitation. Ther Adv Respir Dis 2019; 13: 1753466619878128.

16 Bloem AEM, Mostard RLM, Stoot N, et al. Severe fatigue is highly prevalent in patients with IPF or sarcoidosis. J Clin Med 2020; 9: E1178.

17 Spruit MA, Singh SJ, Garvey C, et al. An official American Thoracic Society/European Respiratory Society statement: key concepts and advances in pulmonary rehabilitation. Am I Respir Crit Care Med 2013; 188: e13-e64.

18 Lunn S, Restrick L, Stern M. Managing respiratory disease. Chron Respir Dis 2017; 14: 45-53.

19 Barratt SL, Morales M, Spiers T, et al. Specialist palliative care, psychology, interstitial lung disease (ILD) multidisciplinary team meeting: a novel model to address palliative care needs. BMJ Open Respir Res 2018; 5: e000360.

20 Similowski T. Treat the lungs, fool the brain and appease the mind: towards holistic care of patients who suffer from chronic respiratory diseases. Eur Respir J 2018; 51: 1800316.

21 Ouellette DR, Lavoie KL. Recognition, diagnosis, and treatment of cognitive and psychiatric disorders in patients with COPD. Int J Chron Obstruct Pulmon Dis 2017; 12: 639-650.

22 Maurer J, Rebbapragada V, Borson S, et al. Anxiety and depression in COPD: current understanding, unanswered questions, and research needs. Chest 2008; 134: 43S-56S.

23 Kew KM, Nashed M, Dulay V, et al. Cognitive behavioural therapy (CBT) for adults and adolescents with asthma. Cochrane Database Syst Rev 2016; 9: CD011818.

24 Verkleij M, van de Griendt E-J, Kaptein AA, et al. Behavioral problems in children and adolescents with difficult-to-treat asthma. J Asthma 2011; 48: 18-24.

25 Yohannes AM, Baldwin RC, Connolly MJ. Mood disorders in elderly patients with chronic obstructive pulmonary disease. Rev Clin Gerontol 2000; 10: 193-202.

26 Willgoss TG, Yohannes AM. Anxiety disorders in patients with COPD: a systematic review. Respir Care; 2013: 858-866.

27 von Leupoldt A, Janssens T. Could targeting disease specific fear and anxiety improve COPD outcomes? Expert Rev Respir Med 2016; 10: 835-837.

28 Janssens T, Van de Moortel Z, Geidl W, et al. Impact of disease-specific fears on pulmonary rehabilitation trajectories in patients with COPD. J Clin Med 2019; 8: 1460.

29 Verkleij M, Maric M, Colland V, et al. Cognitive-behavioral therapy and eye movement desensitization and reprocessing in an adolescent with difficult-to-control asthma. Pediatr Allergy Immunol Pulmonol 2017; 30: $103-112$.

30 Strine TW, Mokdad AH, Balluz LS, et al. Impact of depression and anxiety on quality of life, health behaviors, and asthma control among adults in the United States with asthma, 2006. J Asthma 2008; 45: 123-133.

31 von Leupoldt A, Fritzsche A, Trueba AF, et al. Behavioral medicine approaches to chronic obstructive pulmonary disease. Ann Behav Med 2012; 44: 52-65.

32 Katon WJ, Richardson L, Russo J, et al. Quality of mental health care for youth with asthma and comorbid anxiety and depression. Med Care 2006; 44: 1064-1072.

33 Kunik ME, Roundy K, Veazey C, et al. Surprisingly high prevalence of anxiety and depression in chronic breathing disorders. Chest 2005; 127: 1205-1211.

34 Ferreira DH, Kochovska S, Honson A, et al. Two faces of the same coin: a qualitative study of patients' and carers' coexistence with chronic breathlessness associated with chronic obstructive pulmonary disease (COPD). BMC Palliat Care 2020; 19: 64.

35 Usmani ZA, Carson KV, Heslop K, et al. Psychological therapies for the treatment of anxiety disorders in chronic obstructive pulmonary disease. Cochrane Database Syst Rev 2017; 3: CD010673.

36 Pollok J, van Agteren JE, Esterman AJ, et al. Psychological therapies for the treatment of depression in chronic obstructive pulmonary disease. Cochrane Database Syst Rev 2019; 3: CD012347.

37 Williams MT, Johnston KN, Paquet C. Cognitive behavioral therapy for people with chronic obstructive pulmonary disease: rapid review. Int J Chron Obstruct Pulmon Dis 2020; 15: 903-919.

38 Heslop-Marshall K, Baker C, Carrick-Sen D, et al. Randomised controlled trial of cognitive behavioural therapy in COPD. ERJ Open Res 2018; 4: 00094-2018.

39 Farver-Vestergaard I, O’Toole MS, O'Connor M, et al. Mindfulness-based cognitive therapy in COPD: a cluster randomised controlled trial. Eur Respir J 2018; 51: 1702082.

40 Verkleij M, van de Griendt E-J, Kaptein AA, et al. The prospective association between behavioural problems and asthma outcome in young asthma patients. Acta Paediatr 2013; 102: 504-509.

41 Dodd JW, Getov SV, Jones PW. Cognitive function in COPD. Eur Respir J 2010; 35: 913-922.

42 van Beers M, Janssen DJA, Gosker HR, et al. Cognitive impairment in chronic obstructive pulmonary disease: disease burden, determinants and possible future interventions. Expert Rev Respir Med 2018; 12: 1061-1074.

43 Irani F, Barbone JM, Beausoleil J, et al. Is asthma associated with cognitive impairments? A meta-analytic review. J Clin Exp Neuropsychol 2017; 39: 965-978.

44 Cleutjens FAHM, Spruit MA, Ponds RWHM, et al. Cognitive impairment and clinical characteristics in patients with chronic obstructive pulmonary disease. Chron Respir Dis 2018; 15: 91-102.

45 Barnett K, Mercer SW, Norbury M, et al. Epidemiology of multimorbidity and implications for health care, research, and medical education: a cross-sectional study. Lancet 2012; 380: 37-43.

46 Zwerink M, Brusse-Keizer M, van der Valk PDLPM, et al. Self management for patients with chronic obstructive pulmonary disease. Cochrane Database Syst Rev 2014; 2014: CD002990.

47 Spruit MA, Pitta F, Garvey C, et al. Differences in content and organisational aspects of pulmonary rehabilitation programmes. Eur Respir J 2014; 43: 1326-1337. 
48 Voultsos P, Koungali M, Psaroulis K, et al. Burnout syndrome and its association with anxiety and fear of medical errors among intensive care unit physicians: a cross-sectional study. Anaesth Intensive Care 2020; 48: 134-142.

49 Grace MK, VanHeuvelen JS. Occupational variation in burnout among medical staff: Evidence for the stress of higher status. Soc Sci Med 2019; 232: 199-208. 